\title{
Regional Geography and Quantitative Geography: \\ Compare and Contrast
}

\author{
Maryam Khabazi \\ PhD Candidate in Geography and Urban Regional Analysis \\ University of North Carolina at Charlotte \\ January 2018
}

\section{Compare and Contrast:}

Regional geography emerged in the first half of the 20th century by Hartshorne (1939), the father of regional geography. In his influential book, the nature of geography, he looked back to historical texts and based his claim on the study of nineteenth- and twentieth-century German Geographers like Hettner, Kant, and Humboldt (Hartshorne, 1958). There were other geographers who contributed to the area study before Hartshorne including Fenneman, Preston James, Robert Platt, and their students (Taaffe, 1974). But it was Hartshorne that gave rise to the concept of regional geography. One of the most important works of Hartshorne was translating Hettner's work from German to English. Borrowing the idea of Hettner, Hartshorne asserts that geography is about the study of areal differentiation, and in the center of regional geography is the study of unique places. Places or regions are unique, and the geographer's responsibility is to describe these unique places. Geographers need to know the phenomena within each specific place and familiarized themselves with the intertwined relationships of these things including soils, slopes in mountain areas, urban settlement, rivers, roads, and railroads. Geography is "the product of man's effort to know and understand the combinations of phenomena as they exist in areal interrelation in his world" (Hartshorne, 1958).

Geography, as defined by regional geography, is not like social or natural sciences. Geography does not study a specific object of phenomena, but it studies heterogeneous 
things that are integrated with areas (Hartshorne, 1958). As stated by Taaffe (1974), regional geography on the positive side displays the interconnection and integration of artificially separated phenomena. So, this separation into compartments is more for convenience than the replication of the reality (Taaffe, 1974). In this regard, geography is like history. As history studies unique events, geography in the same vein, studies unique phenomena.

The first step of theoretical approach in regional geography is to identify unit areas (chores) that are homogeneous and cover the earth's surface. In any finite area, however small, many complex factors and semi-independent factors are interrelated. Nevertheless, they vary from point to point. Geographers cannot integrate them except by ignoring these variations for each small unit. Studying each individual chore is not satisfactory for regional study, rather it should study the arrangement of these chores and how these areas are, and how they connected to each other (Hartshorne, 1939).

So, the second step of theoretical approach in regional geography is to study how these unit areas relate to each other in a systematic view to find the structural and functional formation of larger regions, and what relationships of different areas are to create a region. and these added unit areas together form larger units and constitute an entire region (Hartshorne, 1939).

The third step is how these units connect to each other and make an entire region. The regional structure then will be similar to a mosaic of individual pieces that might have very similar characteristics in different units in any region. As Hartshorne describes it "The fiction involves is threefold: we have arbitrarily assumed each small unit area to be uniform throughout; we have delimited it from its neighbors arbitrarily, as a distinct unit (individual); and we have arbitrarily called very similar units identical in character." (Hartshorne, 1939). Systematic geography involves separation of each individual regional structure in order to comprehend its form and its relation to the others. It consists of the analysis of the causal and functional relations of each part to the others. By understanding this, the connections between regions can be understood. Another 
important aspect is that the surface of the earth has moving objects, so geographers should not only consider the form but also the function. Hence, each unit that we consider in a region is uniform in both character and function and when combining units into a region we should consider their functional relations along with their form.

And the forth step is that geographers should know the relationship and arrangement of regions to each other along with the arrangement of unit areas in a region. The goal of regional geography is to identify and understand unique regions, and areal differentiation and division of the entire world that our knowledge of each small unit or region should logically place (Hartshorne, 1939). Sequentially, geography concerned with the reason of similarity and/or differentiation in certain places and what enables people to separate one region from another. This practice became known as areal differentiation (Hartshorne, 1939).

Two different methods are used to study in geography based on Hartshorne idea: systematic geography and regional geography. By systematic or general geography, he means, the examination of specific categories of relationships over the world, and by regional or special geography, he means, "the study of the totality of interrelated phenomena" in unique areas (Hartshorne, 1958). Geographers should have systematic view to understand unique regions and regional relationships. He believes that geography should be both systematic and regional. In addition, he argues that geographers should familiarize themselves with past works in their field (Hartshorne, 1958). Therefore, the purpose of research in geography is to understand unique regions and regional relationships, and the way to execute this kind of research (Hartshorne, 1939).

Albeit, geography, as defined by the idea of regional geography, is concerned about producing generalizable concepts, principles, and laws, like other sciences, but it is more about understanding of individual unique cases (Hartshorne, 1958). One negative aspect of regional geography, as indicated by Taaffe (1974), was that "the interrelationship which had formed the basic rationales for the integrative view were seldom treated 
explicitly. The result again was a paucity of cumulative generalization" (Taaffe, 1974). Even few findings of each region can be transferred to their next regions.

Criticisms towards regional geography have been brought up in 1950s by Schaefer in his paper, Exceptionalism in Geography: a methodological examination, in 1953. Along with Schaefer's criticism, the emergence of spatial view in geography can be traced back to Ullman's stress on spatial patterns in 1950s, Bunge's Theoretical Geography in 1962, and then Haggett's Locational Analysis in Human Geography in 1966. All of them emphasizing on spatial systems and spatial-theoretical view (Taaffe, 1974).

Schaefer criticized Hartshorne's idea that regional geography is an exception. He argued that geography should be seen as a social science. He adopted the positivist philosophy to make his argument that geography is a social science. For geography to be a science, in Schaefer's opinion, it needs to have explanations, and for having an explanation, it needs to have laws. "To explain the phenomena, one has described means always to recognize them as instances of laws" (Schaefer, 1953). Schaefer asserts that the scientific laws of geography concerns about spatial patterns. "Hence, geography has to be conceived as the science concerned with the formulation of laws governing the spatial distribution of certain features on the surface of the earth", and geographers should look for the laws in geography through the spatial patterns and arrangements of phenomena (Schaefer, 1953). Geographical procedures are similar to other social sciences. Geographers need to observe the relationship between spatial patterns to come up with some hypotheses, then through the process of testing the hypotheses, they can verify or reject their hypotheses to establish some laws and regulations for geography. Thus, there is always the process of verification (Schaefer, 1953).

Hartshorne, as a supporter of the idea that geographical material rooted in historicism, asserts that geography deals with unique phenomena and there is no theory for the unique. As a result, he talks about what geography is, rather than Schaefer's idea of what geography should be. Schaefer argues that considering every region as a unique phenomenon without being able to make any laws for geography, is similar to 
questioning laws of physical sciences. This is the matter of degree that how much phenomena are similar, so that extracting laws out of them is possible or not. As Schaefer says "[Scientists] ...apply to each concrete situation jointly all the laws that involve the variables they have reason to believe are relevant." Schaefer states that geography is a nomothetic discipline (law producing) that seeks for laws. In contrary, Hartshorne considers geography as a naïve science or even naïve description. He believes that regional study is the main study in geography and that is an idiographic discipline (fact gathering), which describes unique regions, and when a law is discovered, it is not part of geography anymore. However, Schaefer says that geographers should search for nomothetic laws across spatial structure and without that, geography would just be an immature science (Kitchin, 2015).

Schaefer uses some analogy from physics and economics to reject the idea that geography just focuses on unique regions and unique phenomena. He says that all the sciences cope with some uniqueness in their area to some extent; nonetheless, it does not prevent those sciences to have laws.

After Schaefer criticized Hartshorne and his concept of regional geography, Hartshorne responded to his critiques. However, the way he responded to the critiques of the Schaefer was not convincing since he did not answer to the critiques, but rather he just accused Schaefer of not being clear and not bringing enough examples. Also, he questioned the credibility of the journal that published Schaefer's paper that cannot necessarily refute the credibility of the critiques. He, also, questioned the capability of students who might write part of the article, that if in any case was true, it does not mean that students are not capable of criticizing (Hartshorne, 1954).

Schaefer uses the word exceptionalism and he says that geography is not exceptional at all and it is like other social sciences. This viewpoint is important because it allows researchers to use scientific methods and look for theories and laws thorough testing hypotheses and verification. 
After the Hartshorne-Schaefer debate, geographical thoughts had some changes. Geographers started to study spatial interactions and phenomena rather than areal differentiation. Thus, there was a shift from areal to spatial, and from areal integration to spatial interaction. Geographers started using scientific methods including testing hypotheses, making theories, and finding models. They used statistical techniques and mathematical modeling to analyze quantitative data. Consequently, they hope to find universal laws that can explain and predict spatial patterns and processes to enable us to identify good policy and planning (Kitchin, 2015)

The concept of space also modified after this debate. The absolute space that is an abstract concept in chorological science, substituted by relative space that is about the location of different phenomena in the spatial structure.

The debate between Schaefer and Hartshorne was a turning point in the study of geography and initiated the quantitative revolution in geography in mid 1950s and especially later in 1960s. In this process, the idea of regional geography that just describes unique places replaced by the idea of geography that explains, scientifically verifies, and proves the interaction among spatial phenomena (Kitchin, 2015). "The underlying principles and practices of geography transformed, with description replaced with explanation, individual understandings with general laws, and interpretation with prediction" (Kitchin, 2015).

In order to adopt scientific method, geographers started using some statistical methods to analyze quantitative data. Quantitative data was considered factual and objectively measured, so it was universal and free of subjective bias of analyst (Kitchin, 2015).

Therefore, quantitative revolution, or the view of geography as a spatial science, emerged by the criticism of Schaefer towards regional geography. As was mentioned earlier, he criticized Hartshorne for his chorological view and how he just concerns about unique. Schaefer asked for explanatory laws for geography and he refuted the 
idea that geography is exceptional and considered geography as a social science. The result of this criticism was the emergence of quantitative revolution.

Logical positivism, that is one form of positivism, is an approach that applies scientific principles to social sciences. In logical positivism, scientific methods can be directly used in social sciences, and it can measure, model, explain social behavior, and develop scientific laws. This approach is called naturalism, and it is based on six assumptions (Kitchin, 2015):

1) Verifiable causal relationship for events that involved with human decision-making;

2) People's decision-making occurs because of an individuals' operation of a set of laws;

3) This world that people act and react in it is objective;

4) Scientists are disinterested, and they can observe, test, and prove phenomena without any bias;

5) Human society has a structure that can be changed by observable laws; and

6) The laws of positivism can be applied to societies to be changed in a determinate way (Kitchin, 2015).

Drawing upon logical positivism, scientific methods were adopted for social sciences by Schaefer, who argued that the geography should search for scientific laws among spatial distribution of features on earth's surface (Kitchin, 2015). He criticized Hartshorne regarding the exceptionalist claims that geography is unique from other social sciences. Schaefer argues that geography should be changed from idiographic discipline (describing facts about regions) to nomothetic science (explaining laws in spatial arrangements) (Kitchin, 2015).

The result of these changes towards geography and considering what geography should be instead of what geography is transform the underlying methods and principles of geography from describing to explaining, and from understanding unique to explaining laws. In order to make geography a scientific discipline that applies scientific methods, geographers started using statistical techniques to analyze quantitative data. By using 
these methods, geographers hoped to develop some laws about spatial patterns in the world that can predict future patterns to be able to intervene in the world (Kitchin, 2015). Thus, after criticism towards the regional geography and emergence of quantitative revolution, geography moved towards problem solving and explaining than just describing phenomena. As indicated by Fotheringham (2015), quantitative geographers work includes:

1. Producing meaningful information out of large data sets. Geographers cope with increasingly large spatial data sets collected from satellites, census counts, private companies and governments that needs to be analyzed and make sense out of them.

2. Exploratory data analysis that is done through set of techniques to examine data sets, suggest hypotheses, and so on.

3. Examining randomness and its role in generating spatial patterns and hypotheses testing.

4. Generating mathematical and predicting models of spatial processes (Fotheringham, 2015).

It is fair to mention that during the time that spatial science has been developing, few geographers, that adopted scientific methods in their work, explicitly declared that they use the philosophy of positivism. They used terms such as model, theory, hypothesis, and law, which are the terms of scientific methods, but they did not mention that they use positivistic approach such as GIS science, that is a clear example of spatial science. It is significant to know that it does not mean that all quantitative geography is positivist. Quantitative geography refers to the study of geography that uses quantitative data, and it should not be conflated with the positivist philosophical thought and we should know that few spatial laws were actually identified. (Kitchin, 2015).

Following of some social unrest in late 1960s some criticisms had arisen about the use of scientific methods and its positivistic philosophy in the quantitative revolution. Critics did not criticize the quantitative data per se, but the positivist approach to analyze those 
data. Some critics said that the positivist geography is a form of "spatial fetishism", that geographers use spatial data without considering anything else. Especially, radical and Marxist critics claimed that spatial science just uses observable facts and ignores the role of political and social process in transformation of patterns. In addition, spatial science assumes that people are rational beings, and their decision-making is based on their rationality, however, critics argued that individuals and human society are much more complex, that simple laws in spatial science cannot capture them. Harvey (1973), one of the eminent Marxists and critics of the spatial science, claimed that spatial science is incapable of explaining issues related to class divisions, geopolitical tensions, and ecological problems. In addition, spatial science does not have a normative function in order to give insight about what geography should be, and this normative basis is still a matter of dispute (Kitchin, 2015).

Moreover, humanist geographers criticized spatial science of being peopleless, since it reduces individuals to abstract, rational subjects, and does not consider people's values, beliefs, feelings, and opinions. Because of this critique, humanistic geographers called for qualitative studies of people rather than quantitative studies (Kitchin, 2015).

In addition to the noted critiques, both humanistic and radical critics questioned one of the assumptions of scientific method, that scientists are objective and neutral observers. They argued that the geographers are not separated from the world they are studying, rather they are subjective with their own political and personal perspectives, that at least have impacts on their decision making about what question to ask, and what they should study; these are not value-free choices. Also, feminist geographers had similar criticism and they argued that spatial science follows a masculinist rationality that considers people as rational, predictable, and abstract (Kitchin, 2015).

Despite all the criticisms towards positivist reasoning in geographical work, this approach still remains strong in human geography. Many of the geographers in the area of quantitative methods do not necessarily talk about the philosophical underpinnings of their research, and are not interested in philosophical debates. However, it is crucial 
to address this issue since clearing the philosophical underpinning of a science is important to define the discipline and its praxis, because if it is not addressed, new generations of geographers might be seduced by criticisms about the spatial science (Kitchin, 2015).

Regarding the differences between qualitative and quantitative methods that humanistic geographers discussed about, it should be said that in qualitative methods it is difficult or even impossible to replicate same method in different situations, also, there is no way to measure the accuracy of the results. However, quantitative methods are replicable; it is possible to apply same method to another place. Additionally, quantitative methods are self-critical. There is an error term that is always considered in the equations of quantitative methods, that explains the accuracy of the method. So, the problem of non-quantitative geographies is the lack of enough evidence in their study samples. Just a few numbers of interviewees cannot be considered a reliable sample (Fotheringham, 2015).

In recent years, some quantitative geographers such as Fotheringham (2015) brings up some other problematic issues about some non-quantitative approaches. He asserts one of the problems of non-quantitative approaches is it is impossible to see where the geography is in their research. Much of those researches are much like sociology or political science and the role of space is not explicit. However, if geography is to survive as a separate discipline, it should have a common theme. Quantitative geographers explicitly indicate that we need to investigate space and spatial issues (Fotheringham, 2015).

With emergence of the age of big data in era of technology, future of positivistic science seems to be assured. Like the emergence of GIS in 1990s that has provided a boost to spatial science; modern technologies also seem to provide a new boost to positivistic approach. Big data involve a huge amount of dynamic and intertwined datasets about people, places, interactions, transactions, and territories (Kitchin, 2015). 
By having big data coupled with new complex algorithms and computations, geographers can produce more complex spatio-temporal models of human society and their environment. Geographers can confidently test new hypotheses by relying on more data-intensive analysis to analyze bigger convoluted systems more efficiently, so, in this context, geographers might be able to address some of the critiques leveled previously. "Such an approach is implicitly positivist in its underpinnings. The emergence of big data and computational social science thus has the potential to breathe new life into quantitative geography and positivist forms of geographical analysis" (Kitchin, 2015).

\section{Recognition of "Place": Blending Elements of Regional Geography With Modern Quantitative Techniques}

Contemporary quantitative approach in geography frequently blends elements of regional geography with modern quantitative techniques. They use quantitative methods such as statistics and spatial data analysis with GIS and other spatial analytics software and include some aspects of regional geography in their analysis. They consider specific factors unique to the study area in their spatial and quantitative analysis in hope to confront the criticisms and shortcomings of quantitative methods.

Current quantitative research changes geography in a way that most of the criticism toward it no longer apply. One important critique is that quantitative research has overly simplistic view that tries to find global laws, and it tries to model individuals' action without considering their cognitive and behavioral processes (Fotheringham et al. 2000). However, current quantitative geography emphasizes on local relationships, individuals' spatial cognitive processes, exploratory analysis, and socioeconomic indicators of the study area (Fotheringham et al. 2000). Thus, place gets sufficient attention along with space in contemporary quantitative research.

Here in this part, I am going to investigate one example of current quantitative research, "Analyzing Accessibility Using Parcel Data: Is There Still an Access-Space Trade-Off in 
Long Beach, California?", by Kane et. al, that quantitative methods were used, and some local factors have specifically considered. By looking at Long Beach California, the authors investigate the impact of changes in housing and neighborhood characteristics on the accessibility of business establishments in the neighborhood.

This study, in short, uses "point-based business establishment data to create a typology of thirty-one categories of neighborhood businesses for which accessibility might be beneficial for a resident." Also uses "parcel information from the Los Angeles County tax assessor in 2006 and 2015 to isolate the city's roughly 170,000 individual dwelling units, using a street network topology to generate measures of proximity between homes and each neighborhood business type" (Kane et al. 2017).

The authors use ordinary least squares regression with cluster robust standard error to analyze the data and see the impact of housing development and neighborhood change on the accessibility of business establishments. Variables that have been taken into account include Property characteristics (Building age, Renovated (1/0), Fair market value/unit (log), Condo (vs. large apartment), Detached (vs. large apartment), Multiplex (vs. large apartment), Number of units, Square feet/unit (In), Historic (1/0), Pool (1/0), High-rise (1/0)), Neighborhood characteristics (\%over 65 years old, \%black (nonHispanic), \%white (non-Hispanic), Population density, \%in poverty, Median family income). They also employed geoprocessing methods to create A street network distance-based accessibility measure from parcels to establishments, by using an inverse-distance, or gravity-based measure for all establishment of each type.

This is a quantitative research using statistical methods for data analysis, however, they apply some specific factors that are unique to this case. They consider some qualitative variables regarding the property and neighborhood characteristics in their regression model. "This study's use of higher resolution data allows for the consideration of built environment characteristics alongside neighborhood-level measures while reducing aggregation error and improving statistical identification" (Kane et al. 2017). 
Thus, as we see in this example, authors applied quantitative methods along with considering some unique factors to this specific case. So, they employed qualitative variables in their quantitative analysis. But, the reason that why they blend these factors together is addressing some criticisms towards quantitative research, which some of them were actually true.

One of the criticisms towards the quantitative revolution that brought up with Stamp was that geographers spend long enough to learn their tools including map, cartograms, and other diagrammatic representation, so they do not need to learn about statistics and theoretical economics. However, as well crafted by Burton (1963), this would reduce the geography to use just one tool that is making map and is not adequate mean of displaying the correlations of spatial phenomena (Burton, 1963). Looking at this study by Kane et. al, just using map would not answer their research question. This study definitely needs to consider other tools than maps for analysis.

Another opposition against quantitative revolution was that some variables cannot be measured, which can be true for some variables. However, even for qualitative variables, nominal scales can be used. In addition, critics say that the variables are too complex and numerous for statistical analysis, however, quantitative geographers indicate that it is exactly because of the number and complexity of data that statistical analysis should be applied. In this paper, we see that the authors use nominal variables such as neighborhood characteristics (including black, white) and property characteristics (including condominium vs. large apartments, detached vs. large apartments, multiplex vs. large apartments, and if buildings are renovated or not, have pool or not, and are historic or not). These are some factors unique to the study area that the authors consider.

To sum up, by using the concept of place and considering the uniqueness of each study area, quantitative geographers can address some of the criticisms towards quantitative research such as the one saying it just wants to find generalizable theories. In this case, while considering the uniqueness of each place, quantitative researchers would produce 
theories that can be applied to some specific areas with its own specific condition. They also would accept that there are always exceptions to the theories.

It is fair to say that these criticisms helped quantitative geography to grow and make correction towards its deficiencies. Nowadays, quantitative geographers, along with their hypotheses testing and proposing theories, consider factors unique to their study area to make their studies more accurate.

Therefore, they are not just making theories and generalizable concepts but also making case for each specific place with its unique characteristics in their models. In that case, with some modifications and adding specific variables unique to each place, models can be employed and transferred to some other places.

Despite all of criticisms towards both regional geography and quantitative geography, they still have their supporters, and each has its contribution to the literature of geography. Researchers by using the positive parts of each can improve the quality of research in geography and produce more informative cutting-edge knowledge and make geography a productive and ever-growing discipline that can stand alone from other sciences. By blending concept of regional geography with quantitative research methods, contemporary geography can address criticisms toward each and can find a common language or philosophy to fill the gap between them.

\section{References:}

- Burton, I. (1963), "the quantitative revolution and theoretical geography," Canadian Geographer / Le Géographe canadien, 7: 151-162.

- Fotheringham, A. S., Brunsdon, C., \& Charlton, M. (2000) “Quantitative geography perspectives on spatial data analysis," London; Thousand Oaks, Calif.: Sage Publications.

- Fotheringham, A.S. (2015) “Quantification, Evidence and Positivism," Ch. 25, pp. 306-319.

- Hartshorne, R. (1939) "The Character of Regional Geography," in The Nature of Geography, Association of American Geographers: Washington DC., p. 436-444.

- Hartshorne, R. (1954) "Comment on Exceptionalism in Geography," Annals of the Association of American Geographers, 44: 108-109. 
- Hartshorne, R. (1958) "The Concept of Geography as a Science of Space, from Kant to Humboldt to Hettner," Annals of the Association of American Geographers, 48(2): 97-108.

- Kevin Kane, John R. Hipp \& Jae Hong Kim (2017) “Analyzing Accessibility Using Parcel Data: Is There Still an Access-Space Trade-Off in Long Beach, California?," The Professional Geographer, 69:3, 486-503.

- Kitchin, R. (2015) “Positivistic Geographies and the Spatial Science," Ch. 2, pp. 23-34.

- Schaefer, F.K. (1953) "Exceptionalism in Geography: A Methodological Examination," Annals of the Association of American Geographers, 43: 226-249.

- Taafe, E.J. (1974) "The Spatial View in Context," Annals of the Association of American Geographers, 64(1): 1-16. 